BULLETIN Bulletin hispanique

HISPANIQUE Université Michel de Montaigne Bordeaux

109-2 | 2007

La formation du Parnasse espagnol $\mathrm{XV}^{\mathrm{e}}-\mathrm{XVIII}{ }^{\mathrm{e}}$ siècle

\title{
En viaje al Parnaso
}

Introducción

Pedro Ruiz Pérez

\section{OpenEdition}

Journals

Edición electrónica

URL: http://journals.openedition.org/bulletinhispanique/207

DOI: 10.4000/bulletinhispanique.207

ISSN: 1775-3821

Editor

Presses universitaires de Bordeaux

Edición impresa

Fecha de publicación: 1 diciembre 2007

Paginación: 327-333

ISBN: 978-2-85276-096-7

ISSN: 0007-4640

Referencia electrónica

Pedro Ruiz Pérez, « En viaje al Parnaso », Bulletin hispanique [En línea], 109-2 | 2007, documento 2,

Publicado el 01 diciembre 2011, consultado el 23 septiembre 2020. URL : http://

journals.openedition.org/bulletinhispanique/207 ; DOI : https://doi.org/10.4000/bulletinhispanique. 207 


\section{En viaje al Parnaso}

De los resultados de un Coloquio como el celebrado en la Casa de Velázquez en febrero de 2007 era previsible y deseable dejar caminos abiertos para la reflexión más que conclusiones cerradas. No podía ser de otra manera, dada la naturaleza del tema propuesto y, en particular, por un planteamiento que quería ser expresamente continuación de una serie de reuniones previas, alentadas por François Lopez y Víctor Infantes, como en gran medida han hecho en esta ocasión, y de las que también dieron cuenta y razón las páginas del Bulletin Hispanique. Desde la Casa de Velázquez JeanPierre Etienvre sumó a la tradicional hospitalidad un vivo estímulo, que ya se encontraba en las raíces del proyecto, en tanto que la iniciativa de Nadine Ly resultó determinante para dar forma y cauce a una cita que congregó a especialistas de distintos campos, de cuyas perspectivas complementarias surgió ese diálogo que ahora se recoge en este volumen y que servirá, sin duda, de base para nuevas indagaciones.

Como primera formalización de la moderna noción de canon, el Parnaso se nos presenta también como una construcción in fieri, por más que cada época haya revestido sus modelos con pretensiones de estabilidad. En una perspectiva diacrónica, la definición de un Parnaso participa de los intentos de reconstrucción o, mejor, de construcción de un pasado, ya antes de que Luis Josef Velázquez pusiera la primera piedra y Gil de Zárate asentara para España una historia literaria sometida hoy a continuos procesos de revisión, desde su propia naturaleza como discurso. A esa dimensión, asentada en la concepción medieval y con importantes pervivencias al comienzo de la edad moderna, los nuevos tiempos ańaden una mayor atención al presente. Desde este espacio se revisa lo anterior y en él actúan los poetas, con un objetivo acentuado de situarse en una actualidad inseparable de la conciencia de la historia y sus transformaciones, una cada vez más marcada voluntad de instalarse en un modelo de Parnaso en el que se diluyen los rasgos del modelo clásico, con sus elementos de selección, jerarquía y pervivencia. Acercándose a su moderno valor, el canon es conformado por los propios autores, a partir de una creciente institución que, según señalara Francisco

$B H i$, Tome 109, nº 2 - décembre 2007 - p. 327 à 333. 
Rico, asume la capacidad preceptiva necesaria para este empeño; en su intervención en el Coloquio subrayó la tradicional debilidad de la poesía lírica para ocupar un lugar destacado en el canon, por su carácter minoritario, aunque sus palabras dejaron lugar para reconocer la relevancia que en los respectivos modelos nacionales representaron Dante y Petrarca o Garcilaso y Lope, o la que tuvieron Byron y sus herederos hasta la bohemia para encarnar la imagen del escritor. Su planteamiento apuntó uno de los problemas esenciales a los que se enfrentaba la formación del Parnaso lírico, por la oscilación del género entre el nivel de un genus humilis y su consideración como la forma más depurada de la literatura, sobre todo en unos momentos en que su ejercicio se debatía entre su persistencia como una práctica social y una incipiente profesionalización.

Tal como se configuraba en el horizonte clásico, el Parnaso asumía el carácter de una axiología y se presentaba como un repertorio de modelos de imitación. A la primera dimensión se sometían, además de los géneros y los autores, las distintas lenguas, hasta que esta diferencia se neutralizó con la aparición de los parnasos nacionales. Los modelos, en paralelo, también vieron su principio de autoridad puesto en cuestión, conforme crecía la conciencia autorial, con una confrontación manifestada en la tópica querella de antiguos y modernos, pero también, con el paso del tiempo, en una más directa distinción entre los autores vivos y aquellos a quienes la Parca cortó el hilo, parafraseando la fórmula cervantina en el inicio del «Canto de Calíope». En el monumento erigido en 1649 con motivo de la entrada de Mariana de Austria en Madrid el modelo clásico del Parnaso mantenía en nítida formulación algunos de sus rasgos más determinantes, aunque incorporando ya los vectores de nacional y contemporáneo: allí estaban representados Séneca, Lucano y Marcial, Mena, Garcilaso y Camoens, Lope, Góngora y Quevedo; esto es, la dimensión histórica seguía la tradicional división trimembre, desplegada en el doble eje, pero la nacionalización de todos los componentes y la dimensión imperial apuntada con la asimilación del poeta luso formalizaba una idea de la translatio studii que ponía en crisis la imagen de la decadencia desde la antigüedad grecolatina y destacaba en ella la aportación hispana, coronada por autores de vida reciente y decididamente unidos a la poesía lírica. La persistencia de una nómina reducida y el rasgo de estabilidad derivado de su orden serían los elementos de continuidad de un modelo, cuyo cuestionamiento se realizaba ya de manera implícita con la proliferación de nóminas más abiertas y variadas, cuando no en franca oposición entre ellas y aun en su mismo interior. La fractura es apuntada por Guillermo Serés al hilo de los cambios operados en la relación con los clásicos grecolatinos al irse dibujando una nómina de "clásicos» nacionales; 
el proceso culminaría en el siglo XVIII, con la que François Lopez caracteriza como "generación de 1780», a través de prácticas editoriales y críticas donde el modelo neoclásico se reelabora al gusto moderno. Por el camino, algunos de estos procedimientos, como las antologías o los repertorios bibliográficos, desempeñarían un papel importante, pero no mucho más que otras prácticas menos formalizadas.

En los primeros momentos de su formación el Parnaso nacional se orienta, así, hacia el canon en su noción moderna, inseparable del concepto de «historia literaria», desde su forma más implícita hasta la irrupción del concepto de «Siglo de Oro», estudiado por F. Lopez y A. Blecua, con precedentes insoslayables en Mayans y Luzán, como resaltara Françoise Etienvre. La consideración de una etapa áurea es inseparable de la consideración histórica y del proceso de periodización, de donde surgen parnasos diferenciados. De este modo se produce el desplazamiento desde una ucrónica «república literaria», al modo de Saavedra Fajardo, a la distinción de representantes de distintas épocas y escuelas, no siempre fáciles de conciliar, como sucedía con los propios autores contemporáneos, cada vez más deseosos de ocupar un espacio en el nuevo horizonte abierto con el cambio de perspectiva. Se inicia así la dialéctica discriminatoria que habría de separar autores buenos y malos, en el nacimiento de una crítica imprescindible para una plena institución literaria, hasta desembocar en los manuales y las prácticas escolares (iluminadas por el trabajo de Inmaculada Osuna) a través de una trayectoria jalonada de preceptivas, bibliotecas, Aganipes y otras representaciones del Parnaso. Su vinculación con el principio de autoridad (aun en los casos, no muy abundantes, en que mantiene la independencia de la instancia política) es un elemento de continuidad entre los modelos del Parnaso y del canon: por el contrario, la distinción procede del carácter de dicha autoridad, que en el primer caso aparece con la marca de la sanción confirmadora, mientras que el peso del gusto en el segundo modelo determina su naturaleza cambiante. De ahí procede el dinamismo inherente a la institución literaria con el avance de la edad moderna y las tensiones entre la preceptiva, la demanda del público lector y el papel de la crítica y otros elementos de mediación.

En el desarrollo del discurso temporal acotado en la propuesta del Coloquio, la presencia del componente «nacional» ya desde el siglo XV fue destacada en las intervenciones de G. Serés y Ángel Estévez, como un elemento activo con antelación al resto de los elementos que confluyen en la definición de un canon, como la noción misma de «literatura» y el sentido de la «historia». Ambas se hallan muy presentes en las dieciochescas rotulaciones de "origen, progreso y estado actual», donde late la visión de dinamismo y transformación que habrá de vincularse al canon tras las 
iniciales conformaciones del Parnaso. Los distintos acercamientos a estos primeros esbozos pusieron de manifiesto la diversidad de estrategias e imágenes, a través de la representación del monte, la narración de viajes alegóricos, el diseño de bibliotecas o la realización de repertorios, la colección de retratos y galerías o variadas realizaciones iconográficas, en las que, si no se mantiene la presencia de Apolo y las musas, sí permanece el modelo de la autoridad, convirtiendo en verdaderas auctoritates a los escritores incluidos en la representación. Las antologías estudiadas por Víctor Infantes y por François Lopez encuentran así su complemento en las imágenes visuales analizadas por Pierre Civil, conformando entre todos estos elementos un discurso canonizador cada vez más trabado.

No son desdeñables, sin embargo, los matices y distinciones. Para que exista un Parnaso como cumbre son necesarias las laderas de la base y aun un valle poblado de quienes reconocen los modelos consagrados $\mathrm{y}$, al aceptar su autoridad, los sostienen. Entre los dos extremos se desarrollan las tensiones derivadas del impulso por ascender y la voluntad de permanencia, pero también se generan dos discursos complementarios, aunque el segundo vaya imponiéndose de manera progresiva. Las primeras en aparecer y consolidarse son las estrategias de orden colectivo, con el objetivo de establecer una presencia reconocible de carácter corporativo, la de los escritores, que se presentan a través de galerías, nóminas, bibliografías o repertorios, pero también de antologías y modelos editoriales, cuyos títulos y rasgos característicos cumplen la efectiva función de promover el reconocimiento. Tras la consolidación de esta vía comienzan a perfilarse los discursos tendentes a la canonización individual, que hace sobresalir la realización más sublime sobre el nivel colectivo; así se suceden coronaciones, triunfos y "defunsiones», ediciones comentadas, continuaciones e imitaciones, retratos y panegíricos. Si con las primeras se asienta lo que bien pudiera considerarse un primer "campo literario», los segundos apuntan al establecimiento de una "distinción», por emplear las categorías de Pierre Bourdieu.

Heredera de un modelo basado en la transmisión manuscrita, la poesía lírica mantiene estos procesos, al menos hasta el triunfo editorial de Garcilaso pasado el ecuador del siglo XVI, en los márgenes delimitados de los círculos selectos, desde las cortes cancioneriles a unos cenáculos literarios donde se acomodan las prácticas heredadas a los nuevos espacios tipográficos, con los vínculos y homenajes trabados en los paratextos. En los preliminares y en los elementos editoriales definitorios se da un formato más institucionalizado a los cruces epistolares y los repertorios de ingenios que venían ya decantando el eje del Parnaso a la contemporaneidad más estricta, con unas redes de sociabilidad y de mutuo sostén entre unos autores para quienes la idea de 
la fama desciende a un nivel asequible, mucho más terreno y susceptible de ser alcanzado y disfrutado en vida. La regularización de los modelos editoriales sirvió también para trazar una aduana en el acceso al Parnaso, por recoger otra imagen de Saavedra Fajardo, reflejo de una mentalidad cerrada y conservadora; sin embargo, su valor fue invirtiéndose, para pasar de ser casi un elemento de exclusión, anatemizado por sus efectos de divulgación (de vulgarización), a convertirse en un factor casi imprescindible para el reconocimiento, sobre todo cuando se consolida la institución literaria, como quedó de manifiesto en el trabajo de Giuseppe Di Stefano en torno al romance y el proceso que lo conduce de la ambivalencia de su valoración por los poetas cultos del siglo XV a su consagración en las antologías, ya a mediados del XVII. Entre ambas fechas y entre ambos modelos, en el escenario donde se sustancian los procesos de canonización se ha asentado el papel de cronistas, académicos, tratadistas o bibliógrafos, del que de manera particular ofrece un esclarecedor panorama para las letras portuguesas Jose Adriano de Freitas Carvalho, una auténtica síntesis centrada en el siglo XVII de lo que estamos analizando para España en un arco cronológico más amplio. Los procedimientos son los mismos, y paralelos los resultados; en una variada tipología genérica, estas obras retoman, actualizan y dotan de carácter sistemático las primitivas nóminas de autores, convirtiendo el elogio en algo cada vez más parecido a la crítica literaria, por más que no falten, como en los primeros textos, estrategias más o menos expresas de selección sistemática, con vistas a la elevación al Parnaso o a la exclusión del mismo; las aportaciones de Antonio Pérez Lasheras y de Nieves Baranda y Ma Carmen Marín Pina, respectivamente, ilustraron con claridad estos procesos, con la canonización de los autores aragoneses por Gracián, de un lado, y el destierro de las escritoras, del otro, incluso cuando tienen algún lugar, siempre marginal, en los repertorios.

La trascendencia alcanzada en este proceso por los grandes tratados, en la línea entre Gracián, Mayans y Luzán, reiteradamente destacada, supone, de una parte, la sanción para este tipo de obras sistemáticas, síntesis de preceptiva, teoría, crítica literaria y repertorio antológico, convirtiéndolas, con antelación a las historias literarias en el elemento más determinante en la conformación de un Parnaso, centrado ya en el espacio nacional, aunando criterios y realizaciones, modelos con pretensiones de eternidad y ejemplos históricamente situados; de otra parte, sin embargo, estas verdaderas enciclopedias de la institución literaria plantean de forma más o menos explícita la tensión entre la norma y la diferencia, con la oscilación que ello introduce en el canon y en la dinámica entre la serie y los individuos. Sobre todo en el caso de Gracián, aun centrándose en la noción de ars, en 
la «agudeza de artificio», en la que se detiene de forma más sistemática, adquiere un resalte antes no alcanzado la noción de ingenium, que remite directamente al plano de lo individual, en una formulación moderna y de base científica de la vieja imagen de la inspiración por la musa, y ello con la conocida consecuencia de la consagración de Góngora como «águila de los conceptos». Este extremo de la canonización del individuo descollante habría de encontrar sus antípodas en el tratado de Luzán, pero la dialéctica no se extingue en ninguno de los dos casos, trasladando al plano de la preceptiva o de la teoría un correlato de la señalada convivencia de estrategias: la norma y la excepción, el conjunto y el individuo señero, los géneros y las obras.

Esta línea nos deja ante algunos de los problemas abiertos en la consideración del canon. Los datos recogidos para recomponer el proceso de formación del Parnaso, más que a las puertas de una resolución, nos dejan ante la evidencia de cuestiones abiertas, que atañen a la esencia misma de propuesta canonizadora y sus mecanismos de funcionamiento. ¿Qué es lo que se erige en elemento de un Parnaso? ¿Los autores, las obras o los géneros? El desarrollo del romancero, con sus avatares, diversidad de realizaciones y oscilaciones en su acogida nos sitúa irremisiblemente ante esta cuestión. Su origen popular y su inicial carácter anónimo estuvieron, sin ninguna duda, en la base de su inicial menosprecio, del que no le salvó (quizá todo lo contrario) su relativamente temprano acceso a la imprenta, desde el lugar alcanzado en el Cancionero General a las colecciones monográficas de Martín Nucio menos de medio siglo después. El caso vendría a sustentar la impresión de que el Parnaso está habitado sólo por auctores, entendiendo en ellos, más que un sustento o una aplicación de la auctoritas, una personificación de ese principio insoslayable para el imaginario clasicista. El ascenso del género a la cúspide de las realizaciones nacionales a partir de la ideología romántica, que consagra tanto el genio individual como la manifestación del Volksgeist, vendría a proponer un punto de frontera entre la noción tradicional y un canon entendido en sentido moderno, con un fuerte peso del componente nacional y unos perfiles muy influidos por los cambios de mentalidad y la escala de valores.

Una tarea pendiente en este plano de la revisión de las idées reçues y su proyección en el canon es la relativa al estatuto de ciudadanía de las autoras en la «república de las letras», y en ella la percepción de las estrategias específicas desarrolladas por las mujeres de pluma en su escritura y en su autorrepresentación colectiva no deja de suscitar una cuestión de respuestas divergentes: ¿se debe plantear un canon femenino o se trata de potenciar la dimensión femenina del canon? Entre la singularidad y la identificación, las posibilidades incluyen, efectivamente, la construcción de un canon propio, 
la búsqueda de la inserción y el reconocimiento en el Parnaso o, incluso, el planteamiento de un auténtico anticanon, como inversión del masculinizado modelo dominante. En la alternativa y sus variadas resoluciones se sitúan algunas cuestiones esenciales sobre la propia naturaleza de lo canónico y la construcción del Parnaso, desde la opción más selectiva a la más integradora.

Volviendo a la imagen de la cumbre y las laderas, parece evidente que incluso en la visión más "republicana» de la institución literaria se establece una polaridad entre las figuras señeras y las bases que sustentan la jerarquización, o, si se quiere, en una perspectiva más temporal que espacial, entre las obras memorables y los textos meramente contingentes. Que formen parte de la «gran producción» o la "creación pura» (volvemos a evocar a Bourdieu) puede depender en gran medida de los cambios en la percepción, como apreciamos al considerar las peripecias en algunas consideraciones críticas o «estimaciones literarias». Lo que se impone en la formación del Parnaso desde sus pasos iniciales es la distancia entre la grey y las figuras egregias, si se permite el juego con el concepto, entre una dimensión gregaria, de «poetambre» o autores y obras sin distinción, y una jerarquía que asienta desde su prestigio una función dirigente o modelizadora. Entre los dos extremos las distintas posiciones históricas y estéticas han inclinado su balanza, matizando la imagen del Parnaso o la configuración del canon entre la selecta minoría y las perspectivas más amplias, aunque sin sustraerse casi nunca a las tensiones resultantes.

De algunas de estas tensiones y de sus manifestaciones discursivas y textuales han intentado dar cuenta y razón los participantes en el Coloquio sobre la formación del Parnaso español. Sus aportaciones, sin duda, han arrojado luz particular sobre distintos resquicios del palacio construido para Apolo, sus musas y sus seguidores a lo largo de cuatro siglos, y han permitido avanzar en el trazado de su planta y su alzado, además de situarlo como objeto de una reflexión específica. Sus efectos, sin embargo, como se apuntaba al comienzo de estas páginas, son también los de revelar los espacios en sombra, descubrir nuevas estancias por explorar y, sobre todo, la necesidad de nuevas miradas y estrategias críticas para recomponer un proceso complejo y de amplias dimensiones, pues no en balde se halla en la base de nuestra construcción crítica e historiográfica. Como en tantas otras facetas, el pasado actúa como componente esencial de nuestro presente, y esta consciencia habrá de alentar, sin duda, nuestros gestos de futuro. Sólo cabe esperar que este nuevo paso en el camino sea el origen de más fructíferos avances.

Pedro RUIZ PÉREZ 